\title{
20 years celebrated by the Journal of Educational Sciences - insights, academic achievements and future prospects
}

\author{
Simona Sava ${ }^{\bullet}$, Anca Luștrea•
}

\begin{abstract}
In 2019, the Journal of the Educational Studies (JES) celebrates its 20th anniversary, which is not automatically self-explanatory, not for a Romanian scientific journal in this discipline, and not even for any other prestigious scientific journal. Our journal has faced three main challenges in this period: first, the question of language and internationalization, closely linked to the delivery mode, secondly, the changes of the institutional context, and finally, the development of the discipline. In what follows, we will outline the development of the JES according to the challenges mentioned above, give an overview of the topics and structure adopted by the JES for the last 20 years and highlight the contributions to this special edition on the topic of generational and scientific changes in educational research in this period.
\end{abstract}

\section{Internationalization}

The JES was founded as a national journal, addressing scholars and students in the field of educational sciences, but the need for internationalization increased rapidly. During these 20 years, the majority of those over 10 Romanian educational scientific journals have decided to publish almost exclusively in English and less in Romanian. Such a choice is due to the increased need for internationalization and better visibility, but also it has to do with the constrains of being accepted in the international databases. In addition, the scientific criteria set up by the national bodies of research for the ranking of the journals have also fueled the efforts of the editors to follow this trend. However, such development is rather unfortunate especially for those students, practitioners, and academics who cannot speak English and, in this way they are unlikely to be in touch with the latest research. But, on the other hand, these scholarly journals are forums for popularizing the Romanian expertise and research. Confronted with rather limited financial resources and striving to overcome the impediments of a medium-income country, Romanian researchers have often difficulty in accessing high-ranked journals (Fejes et all., 2019; Hennessy et all., 2019). In addition to this advantage of publishing the

\footnotetext{
-Simona Sava-Professor habil.PhD., Department of Educational Sciences, West University of Timisoara, lidia.sava@e-uvt.ro

-Anca Luștrea-Associate professor, Phd., West University of Timisoara, Romania, University Clinic for Therapies and Psycho-Pedagogic Counselling, anca.lustrea@e$\underline{\text { uvt.ro }}$
} 
journals in English, there is also the benefit of having a more attractive journal for the international community of scholars.

The JES has managed to follow this trend and, at the same time, to remain one of the most well - reputed journals published in Romania. In its 20 years of existence, the journal has developed in three main stages: first, professor Ion Dumitru, the founding editor in chief, stepped back from this position in 2005; one year later, in 2006, prof. Simona Sava took over the chief editorial position, which she has held since then. This change has also meant a new editorial policy for the journal, with a more diverse editorial board and articles published not only in Romanian and not only by Romanian authors, so as to address a wider audience and embrace new perspectives. Up until 2005, the journal was almost exclusively a university journal, with authors from the WUT (Dumitru, Crasovan 2007). Since 2006, the editorial board of JES has made intensive efforts towards internationalization, increased visibility, designing its own website (www.resjournal.uvt.ro). The number of articles published by foreign authors has increased constantly, and since 2008, the journal has published entirely in international languages (English, French, and German), But, in 2009, it decided to publish exclusively in English, when it was accepted in the first international database - Ebsco. In the last ten years, all the issues have enjoyed the contributions of many authors from abroad, and even foreign guest editors.

Besides the opening of the journal to international topics and authors, the editors have invited reputed scholars from abroad to guide the development of the journal and to support it with their experience and expertise. Thus, the scientific board reunites now experts from Germany, Spain, Italy, Denmark, the UK, Greece, Cyprus, Serbia, Latvia, India, Portugal, Hngary, etc. The board has yearly meetings, during which they discuss the achievements of the journal, suggest new topics for the future and recommend new international contributors.

International visibility is not only achieved by publishing in an international language, or by having a diverse editorial board or by choosing new topics, but also by the delivery mode. In the history of the journal, the year 2016 was very successful, when a new editorial board was nominated, a new webpage was designed (https://rse.uvt.ro), and the journal became an entirely open access journal. The editorial board channeled their efforts to meet the editing requirements of the international databases, which made possible the inclusion of the journal in other three prestigious databases (ERIH Plus, CEEOL, CEU). Thus, the JES has managed to turn from a local journal to a nationally and later internationally recognized journal, with a wide European recognition. So far it has managed to be one of the prominent journals of educational sciences in the South-Eastern Europe, acknowledged as such by a number of national scientific bodies in this part of Europe (i.e. the ones from Serbia, Hungary, Latvia, Poland and others).

Comparing the JES with other European journals of educational research, regional ones (i.e. the Scandinavian Journal of Educational Research -SJER - see Lund Martinsen 2018), national ones (i.e. British Journal of Educational 
Technology - BJET - see Hennessy et all 2019), or even European ones (i.e. the European Journal of Research on the Education and Learning of Adults - RELA see Fejes et all 2019), it can be noted that all these journals became international over the years, despite preserving their regional or national titles. In the same vein, it is also shown that their anniversary years are milestones in their development, with new plans for the future, based on their recent accomplishments. If the impressive number of years celebrated, 60 for SJER and 50 for BJET, is proof of their advanced quality, visibility and development, the only 10 years of celebration for RELA, with comparatively equal scientific achievements, argue for the need for more resources to be invested in the development of a scientific journal, whether financial or related to the expertise of the authors. For Romanian based journals, mainly university based, it is quite difficult to rely on such resources that are vital for each journal. Therefore, for a stronger impact and a more accelerated scientific development, joining forces and merging might be an option to be further considered.

Simona Sava-

\section{Institutional background}

Twenty years ago, the founding of the JES coincided with the establishment of two new specializations of the Department of Educational Sciences (DES) of the West University of Timisoara (WUT), the Special Education and the Pedagogy of Preschool and Primary Education (early childhood education). These two specializations merged with the existing specialization of Pedagogy (set up in 1997) in 2002 and 2005 respectively, setting up together the DES, within the Faculty of Sociology and Psychology (FSP). The original idea of the Romanian Institute of Adult Education (IREA) was launched in 1999, and its official launching was in 2000. The IREA was set up as an independent research unit, belonging to the DES, and it has also been a co-editing unit of the JES in all these years.

It should be noted that the JES has a history almost as long as the institutional structures editing it, which emphasizes the the necessity of this publication (Dumitru \& Crasovan, 2007) for a better institutional identity, for enhanced scientific expertise and for the recognition of educational sciences as a wellestablished academic field of study, as Prof. Dorel Ungureanu, the first director of the Department of Pedagogy and later of Educational Sciences (also serving as Scientific supervisor for the JES till 2007) has proposed at that time.

The FSP celebrates its $25^{\text {th }}$ anniversary in 2019. All the four departments reunited under the FSP (The Departments of Psychology, of Sociology and of Social Work, in addition to the DES) were set up after 1990, as until 1989 these specializations had been closed down by the communist regime for almost 17 years. The WUT celebrates 75 years of existence in 2019. If, at the beginning, the WUT was set up as a pedagogical institute for teacher training in different specializations (mathematics, languages, physics and so on), later on all these specializations became distinct faculties. Nowadays, the WUT is the largest university in the Western part of Romania, reuniting 11 faculties, and a distinct 
department of teacher training, and more than 15,000 students. It is the fourth largest national university of the country, a member of the inter-university Consortium "Universitaria", together with the other three main universities in Romania. All these four universities have departments of educational sciences, each of them with their own research journal.

If the other three the DES, set up in 1990, initially had journals as Annals of the university, with a dedicated series of educational sciences, the DES -WUT clearly aimed from the beginning to launch the JES with a wider audience than just the institutional one. The other three universities later founded their scientific journals in the field of educational sciences with different names. Thus, nowadays, the JES is one of the roughly 10 journals of educational sciences, edited in Romania by different universities and educational research institutes.

The recently set up Romanian Association for Educational Research (ARCE), as a member of The European Educational Research Association (EERA), can be a common arena for the existing journals which can merge into a stronger one and be published together, as there is already the successful model of other national educational research associations.

\section{Pedagogy as Discipline}

The JES is concerned with the wide topics of educational sciences, in all their coverage. As it specified in the editorial of its launching number (Dumitru \& Crasovan 2007), the journal was set up with the purpose of providing a forum for enhanced scientific visibility and development for educational sciences as an academic field of study and research. As it will be proven later in the methodological part of this article, the JES has managed to fulfill its scope, addressing all topics in educational sciences and in its specialized subdisciplines, slightly favoring topics related to adult education, and in time it has become a general research hub stimulating communication among researchers

The predominance of topics in adult education is striking in all these years (Dumitru \& Crasovan 2007), this being due to the co-editing team from IREA and to the academic expertise of the educational school of research and academic studies from the WUT, which can be illustrated by the achievements obtained over the years.

20 years of evolution for a disciplinary field can be a long and a short period at the same time. If we look at the major and significant developments taking place in the JES during this time, we might say that it is a long period, which has allowed such changes. It is a period marking a generational change. Therefore, the special topic for this anniversary number has a particular focus: the generational change. This is to say that the members of the scientific board were invited to reflect on the implications of this change in their own contributions, as some of them were doctoral students supervised by the first professors who accepted to be members of the scientific board of the JES in its early beginnings, and currently they are doctoral coordinators themselves, mentoring new generations of educational researchers. Such generational collaboration and 
mutual exchanges are very rewarding, as Irina Maslow (2019) and Emil Păun and Simona Sava (2019) highlight in their contributions. Reflecting back on the developments in the 20 years of publication, Ramon Flecha and his colleagues (Flecha, Gutierrez \& Ruiz-Eugenio, 2019) highlight the move from "edu-myths" to research-based argumentations, empirically proved. This is a general trend in the field of educational sciences, both at the national and the European levels, perfectly illustrated in the evolution of the JES. The articles published in the first years were based on "edu-myths" with a very general application (Dumitru \& Crasovan 2007), whereas for the past ten years we have published a steadily increased number of articles based on empiric studies.

But the field of educational studies itself has dramatically changed in this short period of time, and this change has strengthened the entire evolution of educational sciences regarded as a vital discipline of research. In this sense, a relevant example would be the pedagogy of communication (Soitu, 2019), seen as a field of study on its own right which has been dramatically influenced by the new forms and means of communication that have flourished in these past 20 years. New technologies of information and communication have not only impacted our entire world, but they have changed the world of education in an innovative manner.

The complexity of the educational field is so intricate that only if we look at the contribution of Paolo Federighi (2019) describing the research landscape in adult education, we can have a glimpse ofthe intensive and extensive efforts educational researchers put in structuring, explaining, and advancing the knowledge in educational sciences. Therefore, large fora of debate, large networks and teams of researchers, large amounts of resources are needed to continuously deepen and expand the field of educational research and science, for conceptualizing it, for an improved quality of education, whether nationally or internationally. Such reflections are also mirrored in the celebration speech for awarding the title of Doctor Honoris Causa to Professor Alis Oancea (University of Oxford), also included in this anniversary number. Over the years, the JES has published all the celebration speeches of the distinguished professors of education who became doctor honoris causa of the WUT, whose speeches reflect their extensive expertise and deep reflections in educational sciences. Their outstanding academic work and research have produced great progress in the field of education.

Research in education is dynamic and continuously expanding, reflecting the recent challenges of the societal transformations for education. By its nature, the work conducted in educational research has to look forward to education in the years 2030, 2050 and beyond, to find the best ways for preparing the young generations for a sustainable future and better education. At the same time, educational experts and researchers are expected to look back and capitalize on the lessons education has taught us so far, on the developments of the educational systems and practices, validated over the years, and finally find there evidence for an improved quality of lifelong and life-wide education. 
In conclusion, over the years, the JES presented the valuable contributions of the educational specialists to structuring and advancing the debate and knowledge in the educational field. The focus has been mainly on the Romanian contributions, so as to reflect the developments of the Romanian educational system and educational research. At the same time, the JES has provided open space for valuable contributions to educational research from Europe and beyond, as it can be seen in the next chapters.

\section{Two decade outline}

Twenty years of the journal's history are equivalent to 40 issues, two per year being published. They are collected in 20 volumes.

The purpose of this study is to analyze the profile of the Journal of Educational Sciences, its content and main developments that have taken place in its 20 years of existence, between 1999 and 2019. In addition, future directions andnew lines of research, new research objectives and main themes of interest are advanced in an evidence-based manner.

Four research questions have been developed:

1. Which are the authors` profile?

2. What are the most frequently approached themes?

3. Which research design is prevalent?

4. What are the most frequently used keywords?

To respond to the research questions, a content analysis has been conducted. We aim to analyze, compare and categorize the authors' main features, significant keywords, research themes and research designs.

For our data collection, inclusion criteria have been chosen for all the articles published over the 20-year period since the journal's first publication, 19992019. A total number of 494 articles have been published during this period, including event presentations and book reviews. All of them are content analyzed in this study.

The analysis criteria have been designed following a similar content analysis study conducted by another academic journal, published by Cherrstorm, Robbins and Bixby (2016).The data has beencollected with reference to:

- Each of the issue, in terms of the themes developed by issue (general or special), numbers of articles per issue

- Authors, in terms of gender, geographic region and institutional affiliation

- Articles, in terms of the thematic area covered and type of research design

- Keywords and main themes of research

Both print copies (for the 2000-2005 numbers)and electronic copies (for the 2006-2018 issues) areused in the content analysis.

Main findings and results

The results will be structured in relation to the research questions formulated above. The presented data will refer to the journal issues surveyed, the authorship, the thematic area of the articles, types of research design, keywords and major themes. 


\section{Journal Issues}

Between 1999 and 2018, a total of 39 issues were published, containing a number of 494 articles, including event presentations and bookreviews. The JES is identified by volume, one per year (I-XIX) and issue, 2 per year (1-38). In four years (2000, 2002, 2003 and 2005), the journal appeared just once, both issues being published together, in the same volume. Ever since its first publication, the JES has continued to publish with sustained continuity, and since 2006 all issues have been published regularly, and on time.

General and special issues have been published. Up until 2008, no editorial procedure for planning a general or special issue was in place. From 2000 to 2007, 9 general issues and 3 special issues were published, with no wellestablished order. Since 2008 a procedure for general and special issues has been implemented: the first issue of each year is a general one and the second, a special issue. Out of the total of 39 issues, 14 (35.89\%) arespecial issues and $25(64.10 \%)$, general issues

The themes developed by the special issues are the following: adult education (3 times), competency validation (2 times), special education (2 times), educational psychology ( 2 times), and once, higher education, community development, basic education, special didactics, education and culture.

Table 1

JES`s issues from 2000 to 2018

\begin{tabular}{|c|c|c|c|c|}
\hline Year & Volume & Issue 1 & Issue 2 & $\begin{array}{l}\text { Nr of } \\
\text { articles }\end{array}$ \\
\hline 1999 & & Released issue & & \\
\hline 2000 & I & $1-2$ & General number & 27 \\
\hline 2001 & II & 3 Adult education & 4 General number & 51 \\
\hline 2002 & III & \multicolumn{2}{|c|}{ 5-6 General number } & 27 \\
\hline 2003 & IV & \multicolumn{2}{|c|}{ 7-8 General number } & 27 \\
\hline 2004 & V & $\begin{array}{l}9 \text { Educational } \\
\text { psychology }\end{array}$ & 10 General number & 46 \\
\hline 2005 & VI & \multicolumn{2}{|c|}{ 11-12 Higher education } & 10 \\
\hline 2006 & VII & 13 General number & General number & 31 \\
\hline 2007 & VIII & 15 General number & General number & 24 \\
\hline 2008 & IX & 17 General number & 18 Adult education & 19 \\
\hline 2009 & $\mathrm{X}$ & 19 General number & 20 Adult education & 32 \\
\hline 2010 & $\mathrm{XI}$ & 21 General number & $\begin{array}{l}22 \text { Community } \\
\text { development }\end{array}$ & 33 \\
\hline 2011 & XII & 23 General number & $\begin{array}{l}24 \text { Validation of } \\
\text { competencies }\end{array}$ & 23 \\
\hline 2012 & XIII & 25 General number & $\begin{array}{l}26 \text { Validation of } \\
\text { competencies }\end{array}$ & 24 \\
\hline 2013 & XIV & 27 General number & 28 Educational psychology & 23 \\
\hline 2014 & XV & 29 General number & 30 Basic education & 21 \\
\hline 2015 & XVI & 31 General number & 32 Special didactics & 19 \\
\hline 2016 & XVII & 33 General number & 34 Education and culture & 21 \\
\hline 2017 & XVIII & 35 General number & 36 Special education & 20 \\
\hline 2018 & XIX & 37 General number & 38 Special education & 16 \\
\hline
\end{tabular}


The number of articles per volume varies between a minimum of 10 and a maximum of 46 articles. A total of 494 articles are published $(M=26, S D=9.72)$. In the last 5 years, 97 articles have been published $(M=19.4, S D=2.04)$.The standard deviation per all volumes $(S D=9.72)$ indicates a larger dispersion in the number of articles per volume than in the last 5 years $(S D=2.04)$. As can be seen, a more standardized number of articles per volume occurred naturally. In the last 5 years, a mean of 10 articles per issue have been published.

\section{Authorship}

Table 2 presentsthe distribution of the authors by gender, geographic region, academic degree and institutional affiliation.

Each author is counted onlyonce for a published article, even if they have morethan just one publicationover the years. Gender distribution reflects an unequal proportion: from a total of 635 authors, $430(67.72 \%)$ were females and only $205(32.28 \%)$ were males. There is no statisticsregarding the overall gender distribution of academics in the educational sciences field, but the obtained proportion may reflect the general gender distribution in this field, no gender discrimination being applied.

The geographic region is distributed in two categories: the Romanian contributors and the foreign contributors. Most of the authorsare Romanian $(477,75.12 \%)$ and only $158(24.88 \%)$ are foreigners. Germany is the country with the most foreign authors who have contributed to our journal, followed by Italy and Spain. Other countries that are widely represented are the UK, Greece, Serbia, France, Poland, Denmark, Israel, Luxembourg, Latvia, Hungary, Turkey, and Belgium. In the last five years (2014-2018), 136 authors have been published, out of whom 91 (66.91\%) are Romanian and 45 (33.09\%), foreign. A small increase in the number of the foreign authors can be observed, but not a significant one.

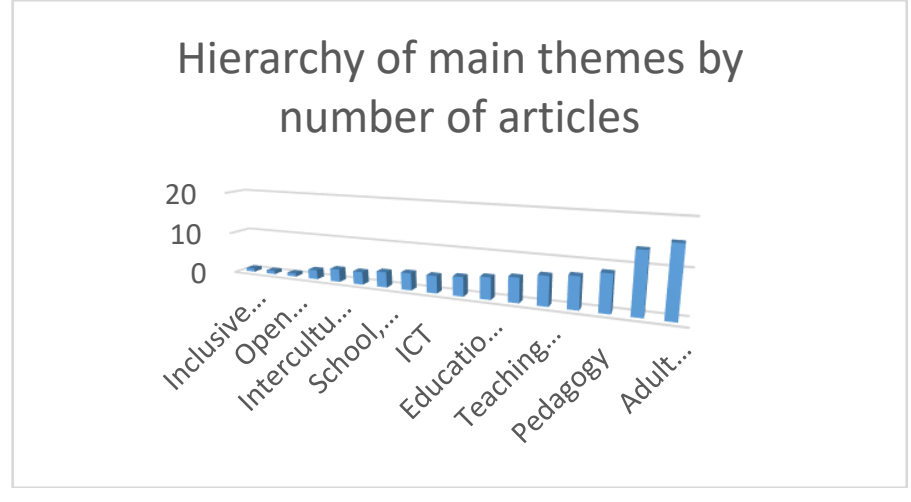

Figure 1: Main themes, hierarchy by number of articles

With regard tothe academic degree criterion, the large majority $(492,77.48 \%)$ have an academic affiliation, $49(7.72 \%)$ are postgraduates, $36(5.68 \%)$ hold a $\mathrm{PhD}$ degree, 24 (3.78\%) are PhD students, 13 (2.04\%) are students and 13,masteral students, and 8 (1.26\%), practitioners. 497 (78.27\%) have an 
academic affiliation and 138 (21.73\%) a non-academic one. A double-blind peer-review process is conducted for each article, so the authors` affiliation is not a publishing criterion. However, the great proportion of academic-affiliated authors derives from their interest in research, with a view to publishing the results of their studiesin a scientific journal.

\section{Prevalent themes}

Table 3 shows the main thematic areas, particularly relevantto the scope of our journal, publicly advertised on the journal website (https://rse.uvt.ro/). 19 educational themes are ranked as the most relevant for the JES. In figure 1, the main themes are presented in the order of the published articles.

The theme with the most articles, 77 (15.58\%), is adult education, followed by educational psychology $(68,13.76 \%)$, pedagogy (the most general theme that includes theoretic approaches to education) $(42,8.5 \%)$, special education (36, $7.28 \%)$, teaching and learning $(33,6.88 \%)$, development and validation of competencies $(28,5.66 \%)$, educational policies $(25,5.06 \%)$, teachers professional development $(22,4.46 \%)$, ICT $(20,4.04 \%)$, higher education $(20$, $4.04 \%)$, school, family, community $(18,3.64 \%)$, management of education $(15$, $3.04 \%)$, intercultural education $(15,3.04 \%)$, primary and preschool education

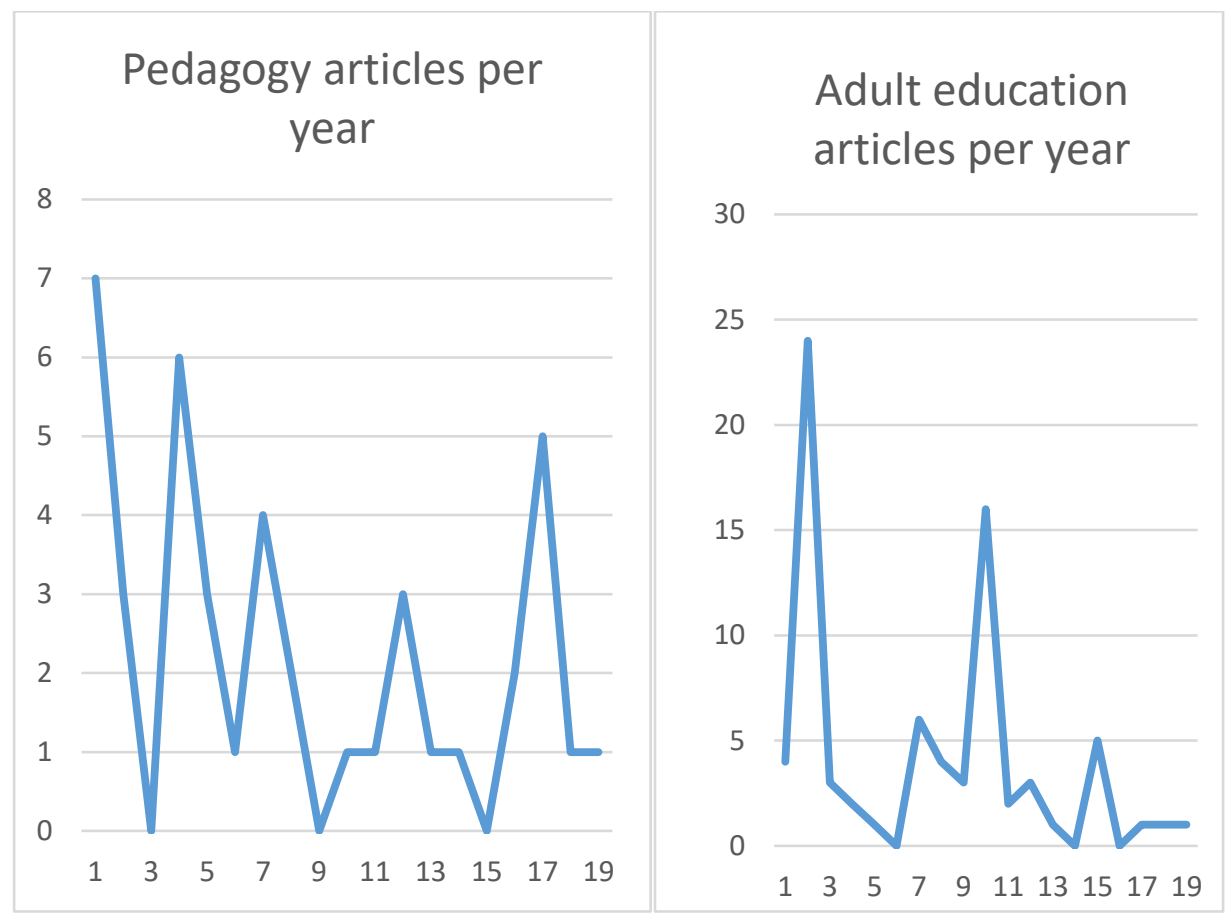




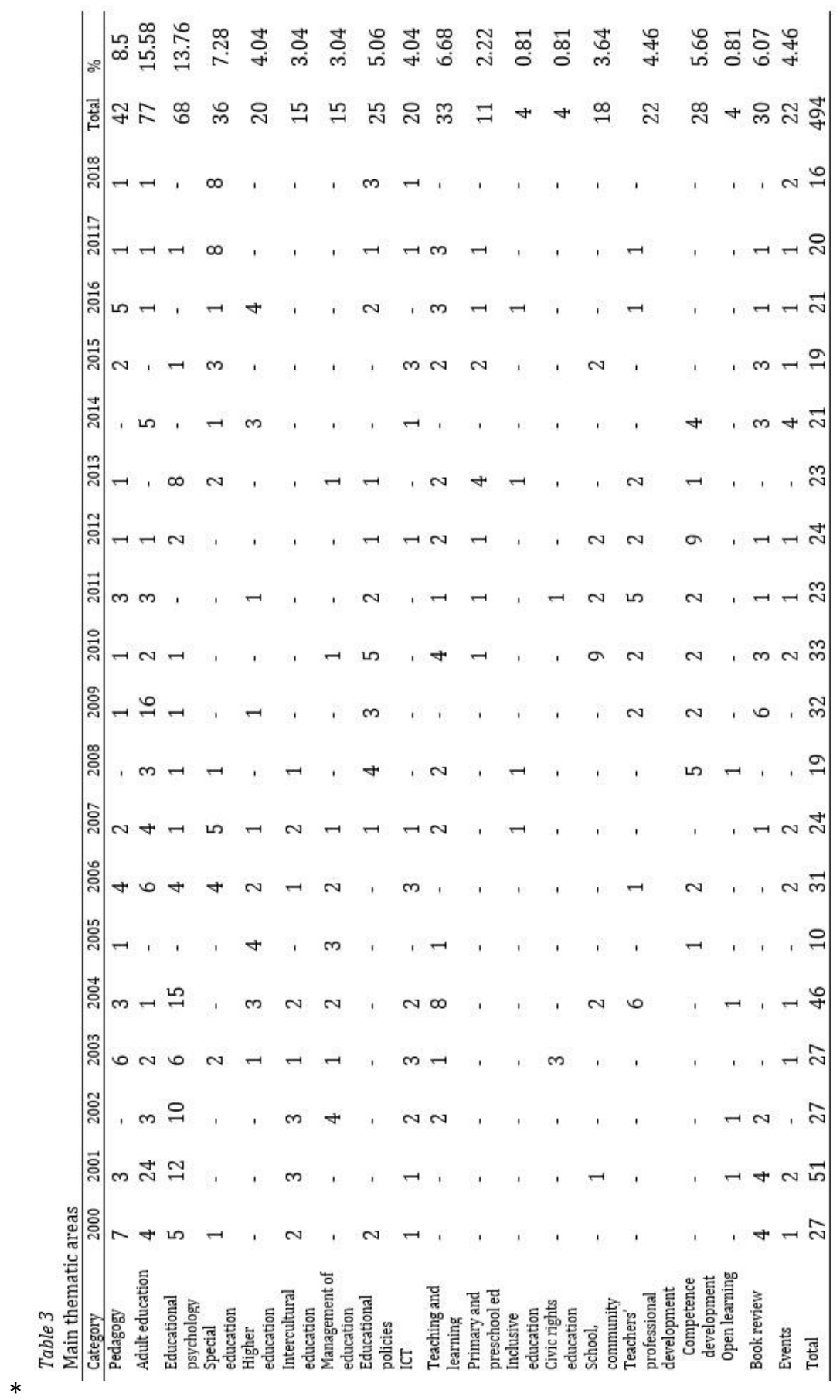




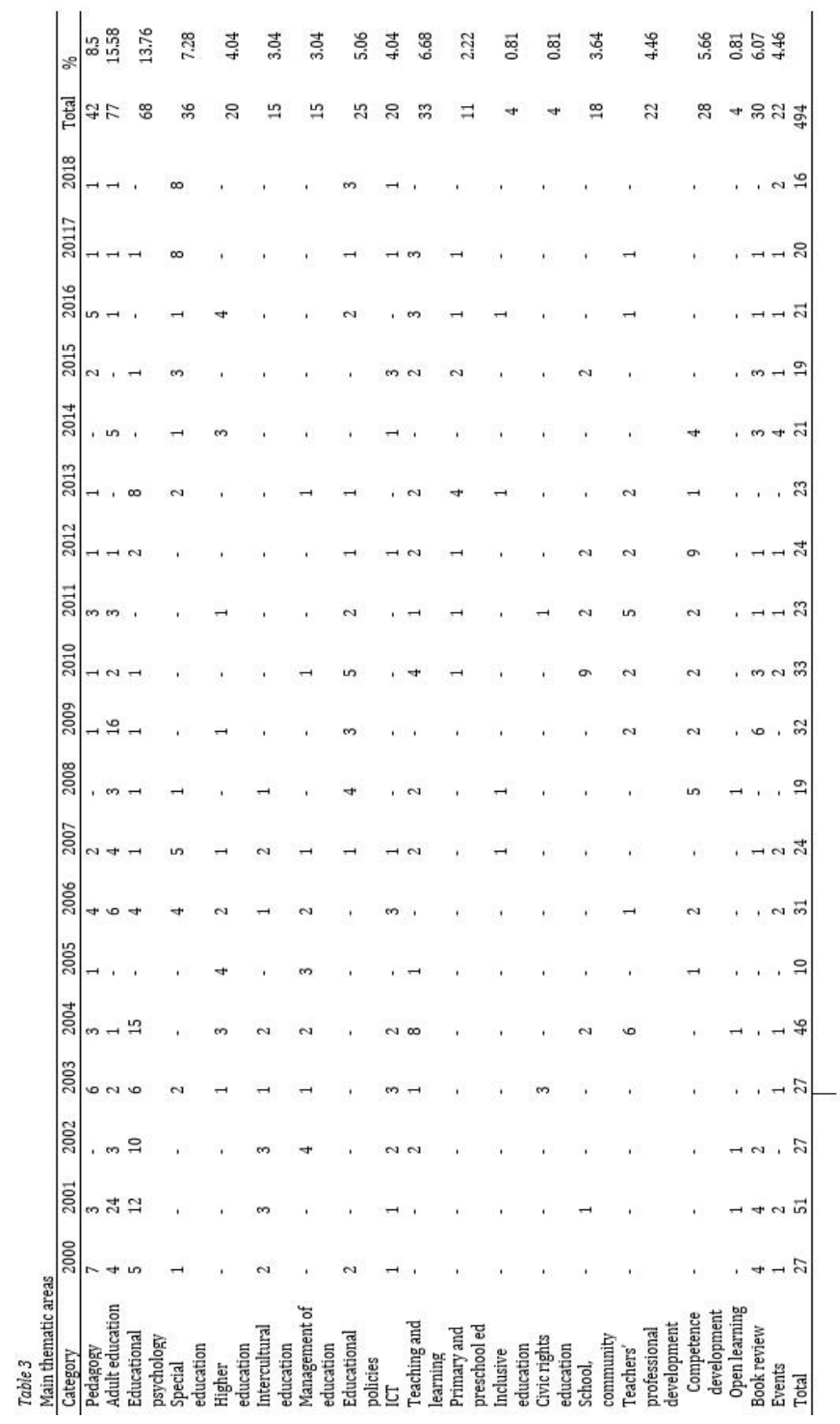




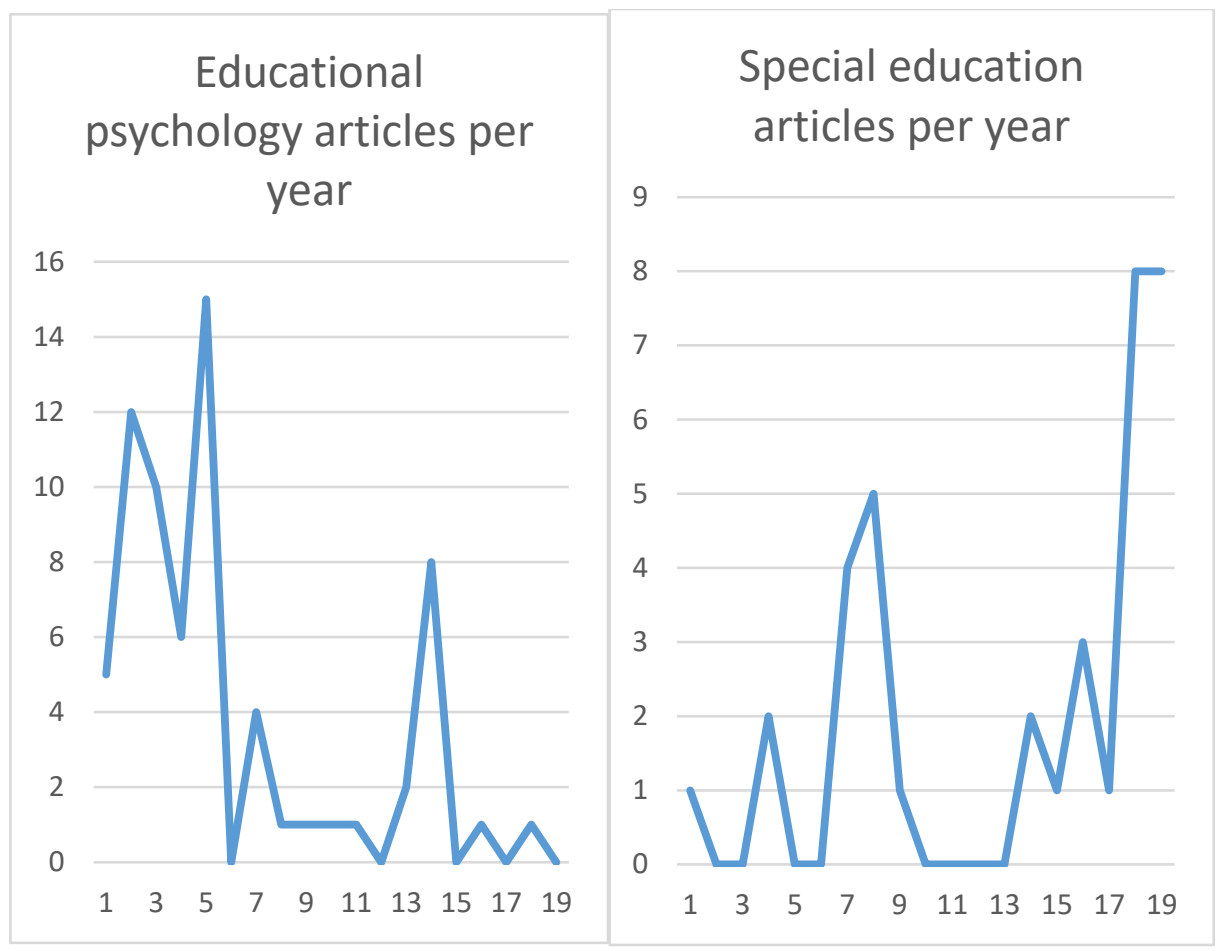

Figures 1-4: Evolution of the number of articles per main themes

(11, 2.22\%), open and distance learning (0.81\%), civic rights education (4, $0.81 \%)$, and inclusive education $(4,0.81 \%)$.

The graphic representation below shows the evolution of the number of articles on the main themes (Fig. 1-4).

For each theme, the number of articles is rather erratic and does not follow a uniform and regular course, which can be explained by the publication of special issues dedicated to specific themes, where the number of articles on the same theme is high. At the same time, arelative continuity in pedagogical articles can be observed anda decrease in adult education and educational psychology articles, while there is an increased interest in the theme of special education. A worryingly small number of articles are dedicated to the primary and preschool education, which should be considered more closely as it is one of the three main domains of educational studies. 


\section{Research design}

In terms of research design, $372(75.3 \%)$ are conceptual, $46(9.31 \%)$ present quantitative studies, 18 (3.64\%), qualitative studies, and $9(1.82 \%)$ use mixed methods. Event presentations $(22,4.25 \%)$ and bookreviews $(30,5.37 \%)$ are also published in every volume (Table 4).

This percentage is similar tothe one reported by Cherrstorm, Robbins and Bixby

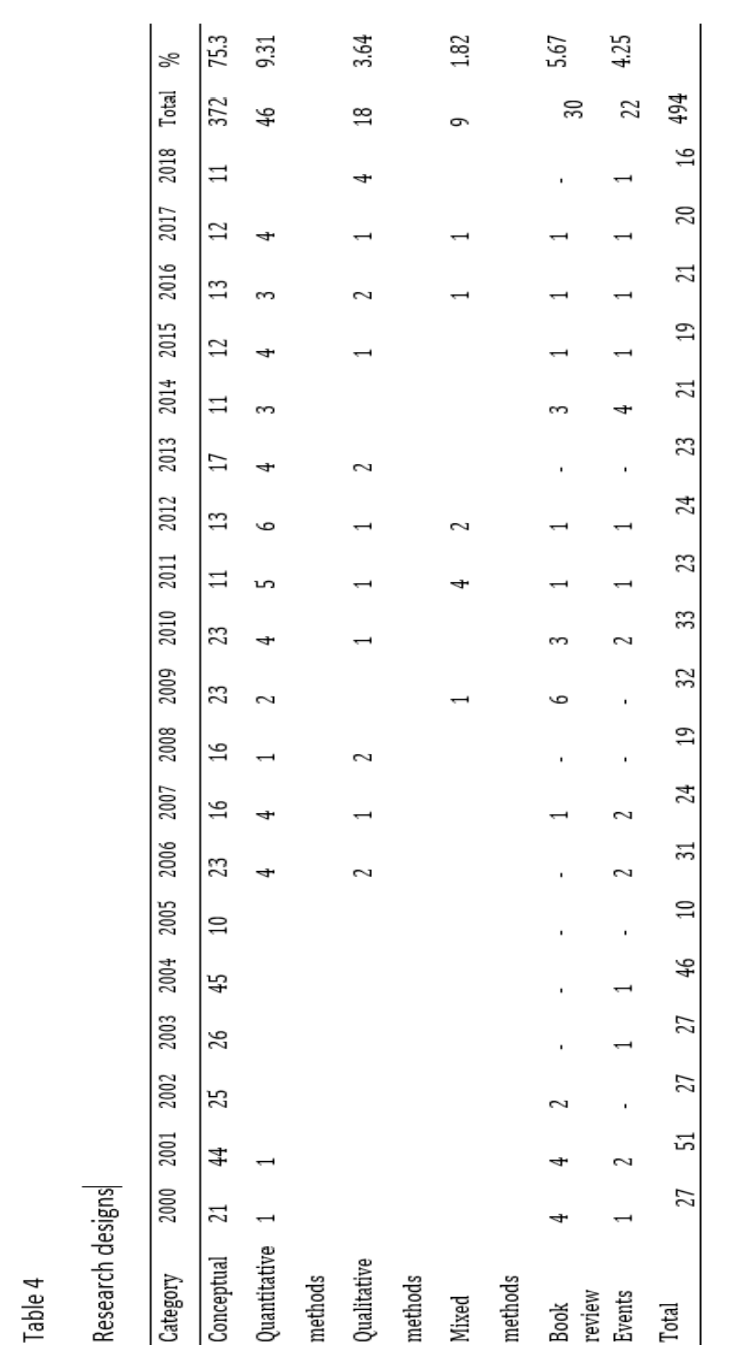
(2016). They found a ratio of $72 \%$ conceptual to $28 \%$ empirical articlesafter analyzing a ten-year period for the Adult Learning journal.

In the last 5 years, the percentage of empirical articles has increased (from 24.7\% per total to $39.17 \%$ in the last 5 years). This is an excellent indicator that the journal is becoming more applied and evidence-based.

Keywords

As presented by Cherrstorm, Robbins and Bixby (2016), we have also created a word cloud, based on the mostfrequent keywords. They reflect the main domains and themes addressed by the articles. The most frequent keywords are education, adult education, learning, lifelong learning, teaching, higher education, special education, disabilities, inclusion, validation of competencies, prior learning, teacher, student, motivation, well-being, assessment, and

professional development.

\section{Years of JES: Discussions and conclusion}

By our overview on the two decades of existing of JES we can identify the journal's profile: how the issues are structured, which are the authors' profiles, which are the main themes addressed and which lines of research are prevalent. In this manner, main research trends can be observed, and an evidence-based practice improvement can be further implemented. 


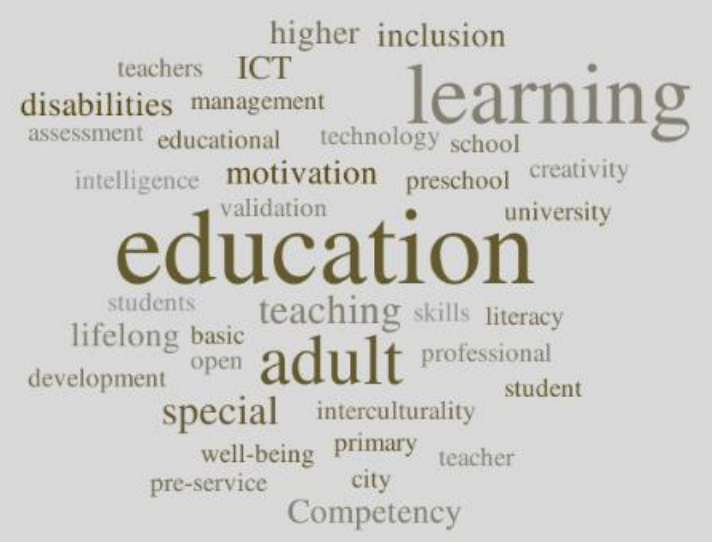

(Wordilitout:

The editorial strategy of publishing a general and a special issue per year is welcomed, because it encourages the diversity of publications, but it also emphasizes the important research aspects for the JES and its institutional editors, the Department of Educational Sciences and The Romanian Institute of Adult Education. It is the publication of special issues that highlights the most recent educational themes not only from the Romanian academic context, but also from other more remote scholarly areas.

Throughout the surveyed period, a mean of 20 articles per volume (10 per issue) established itself as the standard number. This is a reasonable number of articles, ensuring permanent high quality and giving publishing opportunities to researchers.

The authors of the journal are mainly Romanian, but in the last 5 years, the percentage of foreign authors has steadily increased. As this is a Romanian Journal, published by an important Romanian University, it was meant to be a scientific platform for local academics. It promotes the specificity of the Romanian educational context and gives a chance for local qualitative educational research to be published. However, the JES needs to be more open and attractive to all researchers, for whom a dedicated strategy needs to be built, more open to foreign authors and their latest research. Our aim is to redefine our journal as a European Journal that promotes research encouraging educational, national and cultural diversity.

Regarding the thematic areas, we aim to cover extensively all the key themes that are at the heart of our academic interests. Thethemes that have been favored by our publication are as follows: adult education, pedagogy, educational psychology, and special education. They follow closelyvital areas of education and teaching. On the other hand, judging from the educational specialization developed by our university, there is still just a small 
representation for preschool, primary and secondary education. It is clear that these fields need to be more present in our future issues.

The conceptual research is the prevalent type of research design published in the JES. In the last 5 years, the percentage of empirical research has increased rapidly. Although conceptual research is basic in the educational sciences, we intend to correlate more with the current scientific trend by publishing more evidence-based research.

Following these findings, we further aim to publish:

- More articles about European educational research, more articles by foreign authors

- More Articles reflecting the specificity of the Romanian educational system

- More empirical articles, qualitative and quantitative

- More articles in the field of preschool, primary and secondary education

- More articles developed by early career researchers.

Also, as future aims, we would like to mention the introduction of a webbased editorial system, like the Manuscript Central/Scholar-One, to assign a DOI number to each article, and a citation tracker with greater presence in online search engines, greater indexing capabilities, aiming to enhance the technical editing procedures and to ensure increased quality and attractivity to the journal as a whole. We are confident that the new look of our journal cover and its friendly design will have a great impact on our readers.

It is most fortunate to conclude that all the aims formulated in 2007 which were planning further developments (Dumitru \& Crasovan) have been amply fulfilled.

We would like to show our gratitude to our editorial teams for all these accomplishments, to the distinguished colleagues offering their support in their capacity as scientific board members, to all our reviewers for their constructive feedback, to our publisher, the West University of Timisoara Publishing House, and, last but not the least, to all our contributors and readers.

\section{Authorship statement}

The authors of this paper take public responsibility for the content and have had equal contribution in concept development, design, analysis, writing, or revision of the manuscript.

\section{References}

Cherrstrom, C. A., Robbins, S. E., \& Bixby, J. (2016). 10 Years of Adult Learning. Adult Learning, 28(1), 3-11. doi:10.1177/1045159516664320

Dumitru, I., Crasovan, M. (2007). Profilul Revistei de Stiinte ale Educatiei: trecut si perspective. Journal of Educational Sciences. IX(1):142-147.

Fejes, A., Fragoso, A., Jutte, W., Kuratowicz, E., Merrill, B., Olesen, H.S., Wildemeersch, D. (2019). Editorial: RELAs 10-year anniversary: What have we accomplished?.European Journal for Research on the Education and Learning of Adults. 10(1): 7-12. 
Flecha, R., Gutierrez, N., Ruiz-Eugenio, L. (2019). University education of the educational professionals: from the "edu-myths" to the social impact. Journal of Educational Sciences.39(1): 21-32

Federighi, P. (2019). Research Methodology in Adult Learning and Education. Journal of Educational Sciences.39(1): 58-73

Hennessy, S., Mavrikis, M., Girvan, C., Price, S., Winters, N. (2019). BJET Editorial for the $50^{\text {th }}$ Anniversary Volume in 2019: Looking back, reaching forward. British Journal of Educational Technology. 50(1), doi:10.1111/bjet.12731

Journal of Educational Sciences (n.d.), available at https://rse.uvt.ro/

Lund Martinsen, O. (2018). Scandinavian Journal of Educational Research 60th Anniversary. Scandinavian Journal of Educational Research, 62:3, 325-32

Maslo I. (2019). What we can learn from intergenerational collaboration research. Journal of Educational Sciences.39(1): 33-47

Păun E., Sava S., (2019). The reflective dimension of learning in adulthood. Journal of Educational Sciences.39(1): 48-57

Soitu, L. (2019). Pedagogy of Communication. Intersections. Journal of Educational Sciences.39(1): 74-80 